\title{
Antidepressant-like Effects of Aqueous Extract of Salvadorapersica in Rat Model of Depression
}

\author{
Kholoud S Ramadan ${ }^{1^{*}}$, Hoda EA Farid ${ }^{1,2}$ and Raya MM Almarashi ${ }^{1}$ \\ ${ }^{1}$ Department of Biochemistry, King Abdulaziz University, Jeddah, Saudi Arabia \\ ${ }^{2}$ Biochemistry Department, Minufiya University, Egypt
}

"Corresponding author: Kholoud S Ramadan, Faculty of Science, Department of Biochemistry, Al Faisaliah Campus, King Abdulaziz University, Jeddah, Saudi Arabia, Tel: +966551291289; E-mail: ramadankholoud@yahoo.com

Received date: Jun 08, 2016; Accepted date: Aug 24, 2016; Published date: Aug 30, 2016

Copyright: (c) 2016 Ramadan KS, et al. This is an open-access article distributed under the terms of the Creative Commons Attribution License, which permits unrestricted use, distribution, and reproduction in any medium, provided the original author and source are credited.

\begin{abstract}
Salvadora persica (SP) has been used as a medicinal purpose among global Muslim community. Various phytochemical studies on SP reported the presence of saponins, flavonoids, steroids, phenols and tannins. Flavonoids are responsible for antimicrobial, antiallergic, antioxidant, antiradial, anti-inflammatory and antiproliferative activity. The present study was carried out to evaluate the antidepressant activity of aqueous extract of SP on forced swimming test on male albino rats after four weeks treatment. The effect was assessed by immobility time, body weight, vital organ weight, blood glucose, and degree of DNA fragmentation that might happen in leukocyte due to depression. These activities were tested at dose of $900 \mathrm{mg} / \mathrm{kg}$ extracts of SP administered orally for 28 successive days. Rats were divided into two groups (12 animals/group): control group (distilled water) and extract group (SP aqueous extract at $900 \mathrm{mg} / \mathrm{kg}$ PO for two weeks. On day 14, animals will be further classified into four equal groups (six animals each): Undepressed control, depressed rats, extract plus undepressed rats and extract plus depressed for next two weeks. The samples were administered via gavage through oral route. The weight of the animals will be measured every week. It was found that extract significantly $(p<0.001)$ increases mobility time in rats. It also showed significant $(p<0.001)$ decreased in blood glucose and DNA fragmentation as compared to depressed group. The obtained results revealed that SP extract has got significant antidepressant activity. Hence, aqueous extract of SP may be explored further for the management of mental depression.
\end{abstract}

Keywords: Salvadora persica; Depression; Force swimming test; DNA fragmentation

\section{Introduction}

Depression can be defined as a high common disorder with increasing lifetime rates [1].World health organization reported that about 450 million people suffer from behavioral disorder [2] and this percentage represent12.3\% of the global load of disease, and prophesied to rise up to $15 \%$ by 2020 [3]. Depression can be described as a state of mood or energy level that includes lack of motivation, a sense of hopelessness and a loss of physical energy. It is an emotional status that can result from many parts of our life. It is often a debilitating disease that affects a person's work, family, sleeping and ability to assess life. A state of constant depression may suggest a biochemical imbalance or continual stress [4].

The common animal model of depression is Forced swimming test (FST) because it induces a depressive-like manner to conceal antidepressant effect of chemicals and can conclude depressive-like behavior in rats after exposure to other stressors [5]. FST explains a stressing situation which capable of creating a state of lower habit, reflected in the motionlessness induced in animals. The suggested mechanism by which stress causes its effects is via the hypothalamicpituitary-adrenal axis and/or via the sympathoadrenomedullary system [6].

When free radicals are generated in extreme amounts in brain or the enzymatic and non-enzymatic antioxidant defense systems are ineffective, some chain reactions generating oxidative damage to lipids, proteins and DNA are activated and neurons are impaired or even dead [7]. Depressive condition has been accompanied to brain oxidative stress [8].

Focusing in the usage of natural antioxidants is a new strategy for mitigate oxidative damage. Many of the negative effects of oxidative stress are decreased after supplementation with dietary antioxidants [9]. There is an increasing interest in total medicinal plant extracts, the largest value of which may be due to its constituents that subscribe to the modulation of the oxidative balance in vivo. Additionally, the special importance of total plant extracts is that they are easily available products, without purification to apply them in possible prevention of diseases [10]. Reasonably, the application of large quantities of plant extracts is not to be recommends before evaluation of important health issues regarding use of plant phenolics and flavonoids in particular.

The medicinally important species of Salvadora persica L. (SP) also known as miswak, mustard tree and toothbrush tree,distributed mainly in tropical and sub-tropical Asia. Miswak belong to family of Salvadoraceae and every part of the plant is used as a medicinal purpose among global Muslim community. Various phytochemical studies on Salvadora persica reported the presence ofalkaloids salvadorine, flavonoids, steroids, trimethylaine andsalvadoricine. Flavonoids are responsible for antimicrobial, antiallergic, antioxidant, anti-inflammatory and antiproliferative activity. The leaves, roots and stem bark contain an alkaloid trimethylamine [11]. Various ingredients of Salvadora persica have valuable important biological properties, including critical antibacterial and antifungal activity. But till now no scientific works have been reported on its antidepressant activity. In 
light of above information, it is necessary to investigate and develop more effectual antidepressants with lower adverse-effect such as natural product extract (Salvadora persica)especially on the biochemical changes associated with the depression in rats induced by FST.

The mechanism of stress-induced depression is very complex and many actually beneficial artificial chemical antidepressants have decreasing rates of response and even acute adverse-effects [12].

\section{Materials and methods}

\section{Plant material}

The dried roots of SP extract were purchased from a local market in Jeddah, Kingdomof Saudi Arabia, and authenticated by Herbarium, King Abdulaziz University.

\section{Preparation of aqueous extract}

The root sticks were cut into small pieces and ground in grinding machine to fine powder, mixed with distilled water, and extracted for $24 \mathrm{~h}$ at $150 \mathrm{rpm}$ at $25^{\circ} \mathrm{C}$ in a shaker. The mixture was then centrifuged at $3000 \mathrm{rpm}$ for $20 \mathrm{~min}$. The supernatants were subsequently filtered through Whatman No. 1 filter paper and the filtrate was concentrated in rotary evaporator (Buchi Rotavapor R-200) at $70^{\circ} \mathrm{C}$ and was lyophilized. The resulting powder was packed in a glass bottle and stored at $4^{\circ} \mathrm{C}$ until needed. It was dissolved in distilled water to prepare the exact aqueous dose (900mg Kg-1 bodyweight) for orally injection [13]. The extract obtained (20.54\% yield) was prepared in distilled water each time prior to experimentation.

\section{Animals}

Adult male rats (150-200 g) were kept under the constant temperature $\left(25 \pm 2^{\circ} \mathrm{C}\right)$ and light. They were give available ad libitum and tap water. Rats were randomly divided into two groups (12 animals in each group): rats received distilled water orally and served as controls and rats received a single dose of Salvadora persica extract (900 mg/kg PO) for two weeks (extract group). After completion of two weeks, animals were further classified into four equal groups (six animals each): Undepressed control group, depressed rats were daily exposed to FST for $10 \mathrm{~min}$, extract plus undepressed rats received a single dose of Salvadora persica extract orally $(900 \mathrm{mg} / \mathrm{kg}$ ) and extract plus depressed rats were daily exposed to FST for $10 \mathrm{~min}$ and orally administered with plant extract at $900 \mathrm{mg} / \mathrm{kg} \mathrm{b}$. wt. for next two weeks. Following FST, rats were returned to their cages and access food and tap water freely. The weight of the animals was measured every week. All behavioral procedures were carried out in animal models of depression for the evaluation of antidepressant-like effects of extract in groups of rats orally supplemented with aqueous extract following exposure to repeated stress for two weeks.

\section{Blood samples}

At the end of the experimental period ( 28 days), animals were fasted for $8 \mathrm{~h}$ before blood collection in order to cause no interference in the analysis of blood glucose. Blood samples were withdrawn by end tail vein cutting method from overnight fasted animals and blood glucose was measured by one touch electronic glucometer ACU check.

\section{Vital organs weights}

Vital organs (brain, liver, and kidneys) were harvested from scarified rats. They were washed with ice-cold saline solution $(0.9 \% \mathrm{w} / \mathrm{v})$, blotted, and weighted. The weight of each organ was standardized to $100 \mathrm{~g}$ body weight of each animal.

\section{Depression induced by FST}

The FST [14] was done by immersing rats individually in a $60 \times 50 \times 40 \mathrm{~cm}(\mathrm{~L} \times \mathrm{W} \times \mathrm{H})$ filled with water $\left(23-25^{\circ} \mathrm{C}\right)$ from which it could not escape out for $10 \mathrm{~min}$ for 7 days to cause behavioral depression. The rats initially were swam energetically but gradually became immobile; floating in the water with minimum movements of paws and legs to keep their head above the water level [15]. The total duration of immobility was recorded during the next 4 min of total 10 min test. The changes in immobility duration were studied after administrating extract in separate groups of animals. Each animal was used only once. All behaviors of rat in the test were recorded by video camera (Sony-SD/DIGITAL VIDEO CAMERA).

\section{Determination of DNA fragmentation}

The DNA fragmentation level in leukocytes of both control and depressed blood samples is determined according to Perandones et al. [16]. Briefly, $0.1 \mathrm{ml}$ buffy coat layer of blood is added to $2 \mathrm{ml}$ of lysis buffer (Tris-EDTA and Triton X-100). After $15 \mathrm{~min}$ on ice, the samples were centrifuged for $20 \mathrm{~min}$ at $20,000 \mathrm{~g}$ to separate high-molecular weight chromatin from other products. Approximately $2 \mathrm{ml}$ of TrisEDTA buffer is added to the pellet and recentrifuged again. The obtained supernatants from both centrifugations are added together and diphenylamine reagent is added to part of it and to pellet of each sample. After incubation at $37^{\circ} \mathrm{C}$ overnight the optical density is measured at $578 \mathrm{~nm}$ against blank. DNA fragmentation is calculated as follow:

DNA fragmentation $(\%)=$ OD of supernatant/OD of pellet+OD of supernatant $\times 100$

\section{Statistical analysis}

All values are expressed as mean \pm SD. Statistically significance was determined using one-way ANOVA followed by Dunnett's comparison test. $P$ values less than 0.05 were considered significant.

\section{Results}

\section{Preliminary phytochemical screening}

Qualitative phytochemical tests showed the presence of different phytochemicals in water extract of Salvadora persica such as flavonoids, tannins and phenolic compounds as shown in Table 1.

Effect of SP on body weight and vital organ weights: Body weight was evaluated before and after 28 days of treatment is shown in Figure 1 .

Administration of SP extract did not bring significant differences in body weights following 28 days of extract administration. Body weight gain ranged between 41.1 and $69.6 \%$ for the four treatment groups (Table 2). Concerning the relative organs weight to the body weight of rats, the results showed that force swimming test did not produce any 
Citation: Ramadan KS, Farid AEH, Almarashi RMM (2016) Antidepressant-like Effects of Aqueous Extract of Salvadorapersica in Rat Model of

Page 3 of 5

significant effect on the weight of various vital organs of rats after daily administration for 28 days (Table 3 ).

\begin{tabular}{|l|l|l|}
\hline No. & Test for & Water Extract \\
\hline 1 & Carbohydrates & + \\
\hline 2 & Saponins & + \\
\hline 3 & Flavonoids & + \\
\hline 4 & Steroids & + \\
\hline 5 & Phenols and Tannins & + \\
\hline
\end{tabular}

Table 1: Preliminary qualitative tests of root extract of Salvadora persica+ Presence

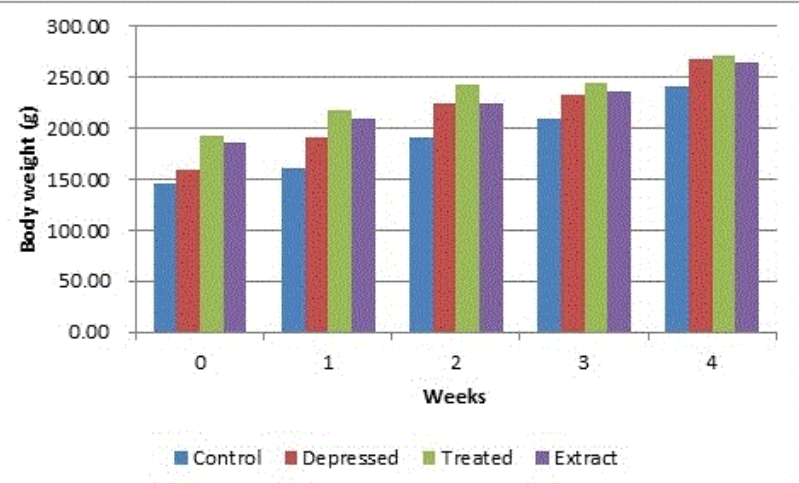

Figure 1: Body weight change of the rats during the experimentation. The results are expressed as the mean \pm SD for 6 animals in each group.

\begin{tabular}{|l|l|l|l|}
\hline Parameters & $\begin{array}{l}\text { Initial weight } \\
(\mathbf{g})\end{array}$ & $\begin{array}{l}\text { Final weight } \\
\mathbf{( g )}\end{array}$ & $\begin{array}{l}\text { Body weight } \\
\text { gain } \\
(\%)\end{array}$ \\
\hline Groups \\
\hline Control & $146.6 \pm 15.2$ & $241.5 \pm 3.0$ & $65 \pm 0.71$ \\
\hline Depressed & $158.8 \pm 17.4$ & $268.3 \pm 5.8$ & $69.6 \pm 0.34$ \\
\hline Treated & $192.6 \pm 3.6$ & $271 \pm 27$ & $41.1 \pm 0.7$ \\
\hline SP extract & $185.6 \pm 5.1$ & $264.8 \pm 8.4$ & $42.7 \pm 0.57$ \\
\hline
\end{tabular}

Values are presented as mean \pm standard deviations.

Table 2: Effect of oral administration of Salvadora persica aqueous extract $(900 \mathrm{mg} / \mathrm{kg}$ b.wt.) after 4 weeks on body weight and body weight gain\% against depression in rats.

\begin{tabular}{|c|c|c|c|c|}
\hline $\begin{array}{l}\text { Organ } \\
\text { weight } \\
\text { (\% body } \\
\text { weight) }\end{array}$ & Control & Depressed & Depressed+Extract & Extract \\
\hline Brain & $\begin{array}{l}0.69 \\
0.13\end{array}$ & $0.67 \pm 0.06$ & $0.66 \pm 0.05$ & $\begin{array}{l}0.64 \\
0.18\end{array}$ \\
\hline
\end{tabular}

\begin{tabular}{|c|c|c|c|c|}
\hline Liver & $3.4 \pm 1.9$ & $3.2 \pm 1.2$ & $3.17 \pm 0.69$ & $3.17 \pm 0.6$ \\
\hline Kidney & $\begin{array}{l}0.68 \\
0.28\end{array}$ & $0.62 \pm 0.21$ & $0.64 \pm 0.06$ & $\begin{array}{l}0.61 \\
0.29\end{array}$ \\
\hline
\end{tabular}

Table 3: Effect of SP extract on relative organ weights of the rats.

Effect of SP extract on depressant behaviors in response to the FST: We examined the antidepressant-like effects of SP extracts in the FST. SP extract treatment in rats reduced the duration of immobility, reducing immobility by a maximum of $32.4 \%$ when administered at a dose of $900 \mathrm{mg} / \mathrm{kg}$ (Figure 2A). SP extracts also significantly increased the swimming time (16.8\%) without any significant change in climbing (Figure 2B).

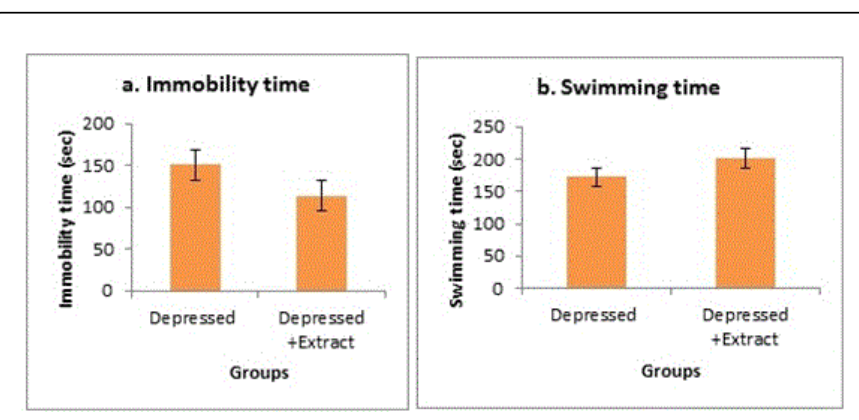

Figure 2: Antidepressant-like effects of treatment with SP extracts on depressive behavior in response to the FST. Immobility (a); and swimming (b) were recorded during FST. Columns show the means $\pm \mathrm{SD}(\mathrm{n}=6) .{ }^{\star} \mathrm{p}<0.05$ vs. the depressed group.

Exposure to force swimming test for 28 days resulted in a significantly increased $(\mathrm{p}<0.001)$ blood glucose level in depressed rats (Figure 3), which was significantly decreased by SP extract at a dose of $900 \mathrm{mg} / \mathrm{kg}$ when compared to depressed rats.

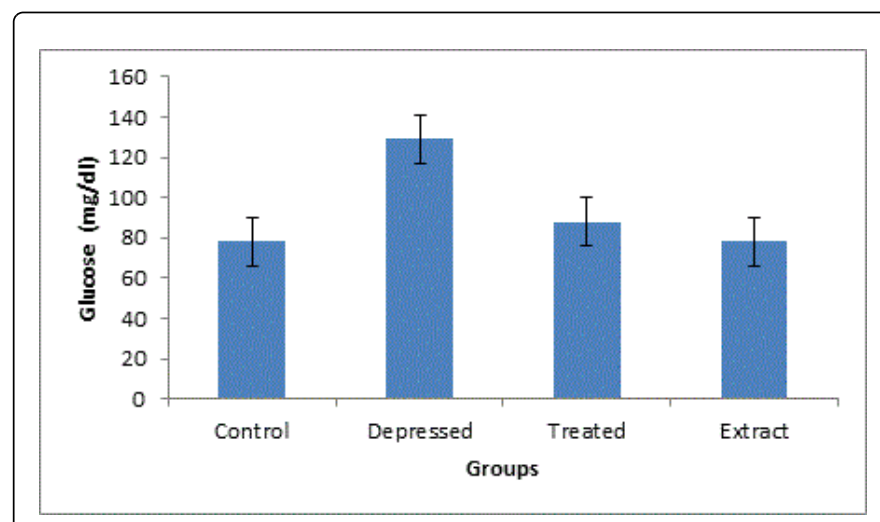

Figure 3: Effects of SP extract $(900 \mathrm{mg} / \mathrm{kg} \mathrm{bw})$ on blood glucose level in control and depressed rats (28 days).The results are expressed as the mean \pm SD for 6 animals in each group. $\mathrm{P}<0.001$ compared with control.

DNA fragmentation: The current study revealed that force swimming test resulted in a significant increase in the percentage of 
DNA fragmentation in blood leukocytes by $25.6 \%$ compared to the control group (Figure 4). On the other hand, treatment with SP extract decrease fragmentation to $5.7 \%$.

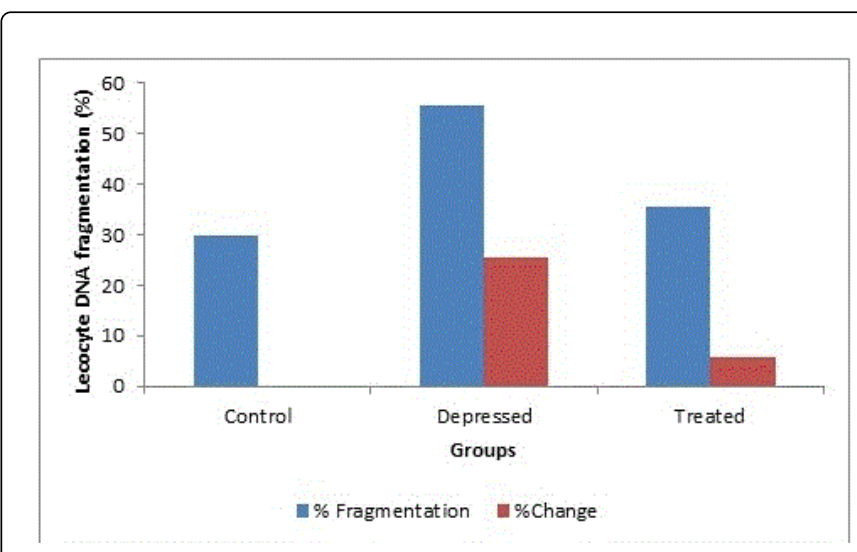

Figure 4: Effects of SP extract $(900 \mathrm{mg} / \mathrm{kg}$ bw) on lecocyte DNA fragmentation in control and depressed rats (28 days).The results are expressed as the mean \pm SD for 6 animals in each group. $\mathrm{P}<0.001$ compared with control.

There was a significant elevation $(\mathrm{p}<0.001)$ in fragmented hepatic DNA level by $85.55 \%$ in cold restraint stress group when compared to the control group. Administration of extract, reduced the level of DNA fragmentation level by $42.53 \%(\mathrm{p}<0.001)$.

\section{Discussion}

The forced swimming test represents a valid animal model for screening antifatigue potency of various bioactive compounds [17]. According to results of phytochemical screening and the literature, the antidepressants like potential might be due to the presence of phenols, glycosides and flavonoids. Flavonoids and glycosides are mostly hydrolysed into their aglycons by mucosal and bacterial enzymes in the intestines, and then converted to conjugated metabolites during the absorption process $[18,19]$. Transportation of these metabolites into the brain tissues via the blood brain barrier and their effect on the central nervous system (CNS) has been recently argued [20,21]. Therefore, one of the antidepressant mechanism of SP is thought to involve flavonoids and glycosides which reach the brain tissues through the metabolizing process, protecting brain function from CNS disturbance and consequently, exerting an antidepressant effect. Thus, extracts of SP may have potential therapeutic value for the management of depressive disorders.

Body weight gain ranged between 41.1 and $69.6 \%$ for the four treatment groups. This result was in contrast to the results obtained by Osman et al. [22] who reported up to $14 \%$ changes in body weight of rats given $M$. oleifera extract for 21days, attributing these changes to the rich nutrient quality of the extract.

Animal models of depression play an important role in the screening and evaluation of antidepressants [23]. The FST is an effective screening tool with good reliability and predictive validity [24] the state of immobility in the FST is reported to mimic the symptoms of depression in humans and can be reversed by treatment with antidepressant drugs [25]. In the present study, aqueous extract of SP produced significant antidepressant like effect in rat in Forced Swim Test (FST). This test is quite sensitive and relatively specific to all major classes of antidepressant drugs [26]. In FST, rats are forced to swim in restricted space from which they cannot escape. This induces a state of behavioral despair in animals, which is claimed to reproduce a condition similar to human depression [27]. Our results show that SP root extracts can decrease immobility time in forced swim test. It is found that SP can produce antidepressant like activity at a dose of $900 \mathrm{mg} / \mathrm{kg}$ body weight after 28 days of treatment. The decrease in the immobility time is accompanied with the increase in swimming time. The precise mechanisms by which SP extracts may produce antidepressant like effect are not completely understood.

The results showed that the swimming time to exhaustion of extract-treated group was significantly longer $(\mathrm{p}<0.05)$ than that recorded for the control group. The maximum forced swimming times were $172.50 \pm 28.3$ and $201.7714 \pm 18.78$ seconds for depressed and extract groups, respectively. The shortness of the length of the swimming time indicates the degree of fatigue [28]. The results therefore indicated that SP extract enhanced the swimming capacity by delaying the onset of physical fatigue in rats. Similar results have been obtained by other workers who tested the ant fatigue potential of various plant extract $[17,29]$.

Stress in optimum quantum acts as stimulator to achieve the best, but when it exceeds, it causes imbalance in some biochemical parameters which leads to suppression in physical endurance [30]. Increased blood glucose level are reversed by antistress agents [31,32]. During stress, blood glucose and cortisol level increases [33] which are found to be significantly reduced in SP extracts treated rats. The regular raised blood glucose like in condition of chronic stress depressed the cognitive functions and immune function. In this study the SP extract $(900 \mathrm{mg} / \mathrm{kg})$ showed regulatory effect on circulating glucose significantly in depressed conditions. The antidiabetic activity of SP may be due to the presence of phytochemicals (flavonoids, tannins, glycosides, sterols, and saponins) [34]. Plants that contain the active principals such as glycosides and flavonoids have antioxidant activity and are said to possess antidiabetic effect. Besidesthis, SP also contain several organic sulphur compounds and it is well known that sulphur derivatives show hypoglycemic effects. In fact, many plants containing sulphur are used traditionally as antidiabetic [35].

DNA fragmentation is very typical of the apoptotic process and its measurement with the diphenylamine colorimetric assay is preferentially used here to evaluate apoptosis in cells [35]. In the present study, it was shown that such depression by force swimming test induced apoptotic cell death including alterations in the immobility time and blood glucose level, could be prevented by the plant extract.

The present findings reveal that Salvadora persica extract might contain principle(s) that possibly exert multiple actions involving different mechanisms in exerting anti-stress effects. The results presented here would provide basic data to examine anti-stress effects of this plant and further in-depth studies could contribute in the development of functional plant materials with anti-stress activities. Currently we are carrying out investigation to understand the mechanism of action and to identify the active components responsible for its anti-stress properties.

\section{Conclusion}

The antidepressant like-effect of Salvadora persica extract was tested. It improved the swimming ability of rats and blood glucose. Further studies are needed to determine the effect of extract on chronic 
physical activity. These findings might be important in the development of new treatment strategies and in the medical practice.

\section{Conflict of Interests}

The authors have no conflict of interests to disclose.

\section{Authors' Contribution}

All authors have read and agreed to the content and the publication of this paper.

\section{Acknowledgment}

The authors have received funds from King Abdulaziz University for the completion of this paper.

\section{References}

1. Elsaid FG, Alzailaie KM, Shati AA (2013)Biochemical and Molecular Alterations Associated with Depression Induced in Rats. Archives des sciences / éditéespar la Société de physique etd'histoirenaturelle de Genève. Experimental Therapeutics, Molecular Targets, and Chemical Biology66:134-154.

2. Rössler W1, Salize HJ, van Os J, Riecher-Rössler A (2005) Size of burden of schizophrenia and psychotic disorders. Eur Neuropsychopharmacol 15: 399-409.

3. Reynolds EH (2003) Brain and mind: a challenge for WHO.Lancet 361: 1924-1925.

4. Umadevi P, Murugan S, Jennifer Suganthi S, Subakanmani S (2011) Evaluation of antidepressant like activity of cucurbita pepo seed extracts in rats. International Journal of Current Pharmaceutical Research 3: 108-113.

5. Takeda H, Tsuji M, Yamada T, Masuya J, Matsushita K, et al. (2006) Caffeic acid attenuates the decrease in cortical BDNF mRNA expression induced by exposure to forced swimming stress in mice. Eur J Pharmacol 534: 115-121.

6. Carrasco GA, Van de Kar LD (2003) Neuroendocrine pharmacology of stress. Eur J Pharmacol 463: 235-272.

7. NiebrAj-Dobosz I, Dziewulska D, Kwieciski H (2004) Oxidative damage to proteins in the spinal cord in amyotrophic lateral sclerosis (ALS). Folia Neuropathol 42: 151-156.

8. Kubera M, Obuchowicz E, Goehler L, Brzeszcz J, Maes M (2011) In Animal Models, Psychosocial Stress-Induced (Neuro) Inflammation, Apoptosis and Reduced Neurogenesis Are Associated to the Onset of Depression. Prog. Neuropsychopharmacol Biolsychiatry353:744-759.

9. Halliwell B (2007) Dietary polyphenols: good, bad, or indifferent for your health? Cardiovasc Res 73: 341-347.

10. Dimitrios B (2006) Sources of natural phenolic antioxidants. Trends Food Sci. Technol 17: 505-512.

11. Abdillahi HS, Stafford GI, Finnie JF, Staden JV (2010) Ethnobotany, phytochemistry and pharmacology of Podocarpus sensus. South Afr J Bot 76: 1-24.

12. Sarko J (2000) Antidepressants, old and new. A review of their adverse effects and toxicity in overdose. Emerg Med Clin North Am 18: 637-654.

13. Badruddeen FS, Siddiqui H, Haque S (2012) Psychoimmunomodulatory activity of Salvadora persica L. (Miswak) extract on stress model in rats. Asian Journal of Traditional Medicines 7: 109-117.

14. Porsolt RD, Le Pichon M, Jalfre M (1977) Depression: a new animal model sensitive to antidepressant treatments. Nature 266: 730-732.

15. Lucki I (1997) The forced swimming test as a model for core and component behavioral effects of antidepressant drugs. Behav Pharmacol 8: 523-532.
16. Perandones CE, Illera VA, Peckham D, Stunz LL, Ashman RF (1993) Regulation of apoptosis in vitro in mature murine spleen $\mathrm{T}$ cells. J Immunol 151: 3521-3529.

17. HaoG, Zhang C, Cao W, Hao J (2014) "Effects of intragastric administration of five oyster components on endurance exercise performance in mice." Pharmaceutical Biology52: 723-728.

18. Bokkenheuser VD, Shackleton CH, Winter J (1987) Hydrolysis of dietary flavonoid glycosides by strains of intestinal Bacteroides from humans. Biochem J 248: 953-956.

19. Walle T (2004) Absorption and metabolism of flavonoids. Free RadicBiol Med 36: 829-837.

20. Youdim KA, Qaiser MZ, Begley DJ, Rice-Evans CA, Abbott NJ (2004) Flavonoid permeability across an in situ model of the blood-brain barrier. Free Radic Biol Med 36: 592-604.

21. Youdim KA, Spencer JP, Schroeter H, Rice-Evans C (2002) Dietary flavonoids as potential neuroprotectants. Biol Chem 383: 503-519.

22. Osman HM, Shayoub ME, Babiker EM (2012) "The effect of Moringa oleifera leaves on blood parameters and body weights of albino rats and rabbits." Jordan Journal of Biological Sciences 5: 147-150.

23. McArthur R, Borsini F (2006) Animal models of depression in drug discovery: a historical perspective. Pharmacol Biochem Behav 84: 436-452.

24. Petit-Demouliere B, Chenu F, Bourin M (2005) Forced swimming test in mice: a review of antidepressant activity. Psychopharmacology (Berl) 177: 245-255.

25. Renard CE, Dailly E, David DJ,Hascoet M (2003) Monoamine metabolism changes following the mouse forced swimming test but not the tail suspension test. Fundam Clin Pharmacol 200317: 449-455.

26. Detke MJ (1995) Active Behavior in the rat forced swim test differentially produced by Serotonergic and noradrenergic antidepressants. Psychopharmacology 121: 66.

27. Willner P (1984) The validity of animal models of depression. Psychopharmacology (Berl) 83: 1-16.

28. Tanaka M, Nakamura F, Mizokawa S, Matsumura A, Nozaki S (2003) "Establishment and assessment of a rat model of fatigue." Neuroscience Letters 352: 159-162.

29. Choi EH, Kang J, Cho JY(2012) "Supplementation of standardized lipidsoluble extract from maca (Lepidium meyenii) increases swimming endurance capacity in rats." Journal of Functional Foods 4: 568-573.

30. Kannur DM, Kulkarni AA, Paranjpe MP, Navangul MV (2008) Screening of antistress properties of herbal extracts and adaptogenic Agents. Pharmacognosy Reviews 2: 95-101.

31. Sumanth M, Mustafa SS (2007) Antistress, adoptogenic and immunopotentiating activity roots of Boerhaavia diffusa in mice. International Journal Pharmacology 3: 416-420.

32. Sumanth M, Mustafa SS (2009) Antistress, Adoptogenic Activity of Sida cordifolia Roots in Mice. Indian J Pharm Sci 71: 323-324.

33. Lakshmi BVS, Sudhakar M (2009) Screening of Psidium guajava leaf extract for antistress activity in different experimental animal models. Pharmacognosy Research 1: 359-366.

34. Arora M, Gupta VK (2011) "Phytochemical and biological studies on Salvadora persica wall: review." Pharmacologyonline1: 591-601.

35. Lanjhiyana S, Garabadu D, AhirwarD(2011) "Antidiabetic activity of methanolic extract of stem bark of Elaeodendron glaucum Pers. in alloxanized rat model," Journal of Advertising and Applied Science Research 2: 47-62

36. Chida Y, Sudo N, Kubo C (2006) Does stress exacerbate liver diseases? J Gastroenterol Hepatol 21: 202-208. 